\title{
Within-group spatial position and activity budget of wild sooty mangabeys (Cercocebus atys) in Taï National Park, Côte d'Ivoire
}

\author{
Bomey Clément GBA ${ }^{1,3,4,5^{*}}$, Jean-Claude Koffi BENE ${ }^{2,4}$, Zoro Bertin GONE BI ${ }^{1,4,5}$, \\ Alexander MIELKE ${ }^{6,7}$ and Inza KONE ${ }^{1,4}$
}
${ }^{1}$ Laboratoire de Zoologie et Biologie Animale, Unité de Formation et de Recherche de Biosciences, Université Félix Houphouët Boigny, Abidjan, 22 BP 582 Abidjan 22, Côte d'Ivoire.
${ }^{2}$ Laboratoire de Biodiversité et Ecologie Tropicale, Unité de Formation et de Recherche d'Environnement, Université Jean Lorougnon Guédé, Daloa, BP 150 Daloa, Côte d'Ivoire.
${ }^{3}$ Max Planck Institute for Evolutionary Anthropology, Leipzig, Deutscher Platz 6, 04103 Leipzig, Germany.
${ }^{4}$ Centre Suisse de Recherches Scientifiques en Côte d'Ivoire, Abidjan, 01 BP 1303 Abidjan 01, Côte d'Ivoire.
${ }^{5}$ Taï Chimpanzee Project, Centre Suisse de Recherches Scientifiques en Côte d'Ivoire, 01 BP 1303 Abidjan 01, Abidjan, Côte d'Ivoire.
${ }^{6}$ Department of Psychology, University of Portsmouth, King Henry Building, PO1 2DY, Portsmouth, United Kingdom.
${ }^{7}$ Primate Models of Behavioural Evolution, University of Oxford, 64 Banbury Road, OX2 6PN, Oxford, United Kingdom.
*Corresponding author; E-mail: clement.formula@gmail.com; Tel: +22507614618

\section{ACKNOWLEDGMENTS}

My sincere appreciation goes to the Max Planck Institute for Evolutionary Anthropology (MPI-EVA) and Taï Chimpanzee Project (TCP), and the Centre Suisse de Recherches Scientifiques en Côte d'Ivoire (CSRS-CI) for funding this study. The Max Planck Society provides core funding for the TCP since 1997. BCG received a joint student grant from the CSRS-CI and the MPI-EVA.

\begin{abstract}
Within social groups, feeding competition and predation pressure affect individual spatial position. The costs and benefits associated to each position are likely to influence the time that individuals allocate to different activities. Whether the effect of spatial positioning on activity budget differs between individuals of different sex or dominance rank remains unclear. This study aimed at investigating the effect of within-group spatial position on the activity budget of male and female sooty mangabeys. Focal behavioral observations was used to collect the individual location and behavior every 15 minutes ( $\mathrm{N}=5115$ locations) on 29 individuals from a wild group of sooty mangabeys (Cercocebus atys) in the Taï National Park. The joint effect of rank, sex and spatial position on individual's activity budget was investigated. Females were more central in the group and both fed and rested more than males, independently of their rank. High-ranking individuals from both sexes were more likely to be central and both fed and rested longer than low-ranking ones. Females and highranking individuals from both sexes benefit from their social status by adopting spatial positions in the community that could influence their fitness positively. These results are discussed to improve our understanding of social dynamics in wild primates.

(C) 2019 International Formulae Group. All rights reserved
\end{abstract}

Keywords: Spatial position, primates, socio-ecology, social dynamics. 


\section{INTRODUCTION}

Competition and predation pressures are the factors that determine the major costs and benefits of occupying a specific spatial position in a social group, and shape the evolution of social systems (Morrell and Romey, 2008). They have direct effects on the fitness of animals that can vary across sexes due to the sex differences in the fitness outcomes (Hegab et al., 2018). In primates, the priority for females is food to meet their high-energy requirements during the different reproductive states such as pregnancy and lactation (McCabe and Fedigan, 2007). For males, the priority is access to mates, since the main constraint on their reproductive success is the frequency of access to fertile females to mate (Koenig et al., 2013). To access resources efficiently and effectively increase reproductive success, hierarchy plays an important role for both females and males in many primate species with priority of access to resources being rank-dependent (Murray et al., 2006). High-ranking individuals can outcompete others for optimal social and spatial positions that give them access to preferred resources.

Individuals in a group experience the advantages and disadvantages of group living differently, with an important impact of the spatial structure of the group. Occupying different spatial positions within the group is strongly linked to different fitness costs and benefits (Morrell and Romey, 2008). Individuals in a central position are less exposed to predators than those at the periphery. Indeed, peripheral individuals devote more time to vigilance than to foraging in several primate species (Miller, 2002; Hirsch, 2007). They benefit less from the conspecific vigilance and dilution effects, since they have fewer neighbors than those in the center. Therefore, to increase their ability to exploit resources while dealing with constraints such as predation risks and conspecific competitors, individuals in animal groups are expected to compete for central positions. Their success and motivation should be based on their sex and their dominance rank (Di Bitetti and Janson, 2001).

Being in a central position can be associated with higher social costs. Intragroup competition for resources such as food should be stronger at the center, where animal density is highest and where social interactions should be more frequent and intense (Hirsch, 2007). Previous studies showed that spatial position influences the time allocated to foraging activity in primates. Thus, the spatial position occupied by individuals within the group represents a trade-off between costs and benefits on their fitness that are likely to influence the time allocated to different activities, according to individuals' social status (Cebus apella: Di Bitetti and Janson, 2001). The activity budget, defined as an animal's allocation of time among different behaviors, is strongly correlated with the environmental conditions and social characteristics in primate groups (Di Fiore and Rodman, 2001), and can vary according to the spatial positions of individuals in relation to the rest of the group. Understanding how sex, dominance rank and spatial position affect activity budgets is important to improve the scientific knowledge related to the social dynamics in a large mixed-sex group frequently seen in primates.

To contribute to filling this gap, the impacts of within group spatial positions, sex and dominance rank on activity budgets were investigated in a group of wild sooty mangabeys (Cercocebus atys). Sooty mangabeys live in large multi-male multifemale groups with philopatric females and migratory males. Most males outrank most females and both sexes show a linear and stable dominance hierarchy (Range and Noë, 2002; Mielke et al., 2017). Mainly terrestrial and frugivorous, they spend most of their daily time $(63.3 \%)$ foraging rather than resting (26.4\%) and traveling (10.3\%) (McGraw et al., 2007). Yet, the changes in activity budgets depending on the spatial position, sex and dominance rank of individuals remain largely unknown in sooty mangabeys.

The main question of this study is how within-group spatial positioning affects male and female activity budget dynamics of sooty mangabeys at different points of the hierarchy, while controlling for the effect of food abundance. Regardless of dominance rank and spatial position, both females and males are expected to spend more time feeding than resting or traveling, since mangabeys spend most of their daily time budget foraging 
(Range and Noë, 2002). Because of the differences in the evolutionary priorities across sexes with females more influenced by food than males (McCabe and Fedigan, 2007), female activity budget is expected to show a stronger focus on feeding than male activity budget. Since the central position is a safe spatial position to reduce predation pressures and foraging is the most risky activity (Miller, 2002), individuals are expected to be more likely to feed in central positions within the group. In contrast, individuals in a more peripheral position are expected to be more likely to be observed traveling than those in the center. Males are expected to remain at the edge of the groups because they are less vulnerable to predators than females and infants (Heesen et al., 2015). The most dominant individuals are expected to be the most central depending on their preferences for feeding positions, while subordinate individuals are expected to be more peripheral, avoiding the high level of competition for resources in the center (Di Bitetti and Janson, 2001; Heesen et al., 2015). Since individual positioning could affect foraging success, dominant sooty mangabeys, as well as female sooty mangabeys, are expected to occupy preferred central position with respect to both feeding success and safety contrary to subordinate sooty mangabeys (Range and Noë, 2002). The aim of this study was to investigate the effect of within-group spatial position on activity budgets of male and female sooty mangabeys at different levels of the hierarchy.

\section{MATERIALS AND METHODS Study area}

Our study was carried out in Taï National Park located in the South West region of Côte d'Ivoire. The region has two wet seasons (April-June and SeptemberOctober) and two dry seasons (July-August and November-March). Mean monthly temperatures range from $21.7{ }^{\circ} \mathrm{C}$ to $30.1{ }^{\circ} \mathrm{C}$, while rainfall averages $1893 \mathrm{~mm}$ per year (Anderson et al., 2005).

\section{Study group and species}

The study was conducted on a group of fully habituated 50-63 wild sooty mangabeys, with an average of 15 adult females and 4 adult males, 3 sub-adult females and 4 subadult males, 11 juvenile females, and 16 juvenile males, identified by natural markings at the beginning of the data collection period. Since males are usually non-residents in sooty mangabeys, there were male immigrations and emigrations during the course of the data collection. Adult individuals (females: $\geq 5$ years; males: $\geq 7$ years) and sub-adult individuals (both sexes: $>3$ years) (Range and Noë, 2005) were equally considered in this study.

\section{Data collection}

Data were collected over 14 months from April 2015 to May 2016. A customized application of CyberTracker data collection software was used to collect behavioral data in the first three weeks of each month. Hourlong focal individual samples of female $(\mathrm{N}=18)$ and male $(\mathrm{N}=11)$ individuals were used to record within-group spatial position only when the observer has a clear overview of the group and activities of focal individuals' instantaneously at 15-min intervals ( $\mathrm{N}=5115$ samples). Furthermore, supplant interactions were recorded ad libitum (Altmann, 1974) to determine the dominance hierarchy (Range and Noë, 2002).

Data on phenology of fruit plants eaten by mangabeys were recorded visually with binoculars the last week of each month along defined transects (Ngueguim et al., 2011). Fruit plants included only trees and shrubs with a Diameter at Breast Height (DBH) $\geq 10 \mathrm{~cm}$ (Tiebre et al., 2014) and lianas with a DBH $\geq 5 \mathrm{~cm}$ (Nascimento and Laurance, 2002) from 42 species constituting the diet of mangabeys. These plants were inventoried in 40 botanical plots of $2,000 \mathrm{~m}^{2}$ each created along four linear transects of $2 \mathrm{~km}$ length each, equally spaced by $500 \mathrm{~m}$. The area covered by the four transects represented more than $80 \%$ of our study group territory.

\section{Data analysis \\ Variables: activity, spatial position, dominance rank and food availability}

Feeding, resting and traveling were recorded as main activity states at the $15 \mathrm{~min}$ interval. Individuals were considered to be resting when they were sitting or lying down; and this includes social behaviors like 
grooming and playing. Individuals were recorded as traveling when they were moving from one point to another on the ground or in the trees, running, walking or climbing steadily. Individual were feeding when they were manipulating and/or ingesting food items but also when they were searching and visually scanning the forest floor or their environment, occasionally putting objects in their mouth (Range and Noë, 2002; Fonkwo et al., 2015).

The different spatial positions (central, border and periphery) were indicated in relation to the presence of other members of the group in a circular area of 10 meters radius around the focal individual at each $15 \mathrm{~min}$ interval. Since sooty mangabeys are predominately terrestrial (McGraw et al., 2007), the focal animal was considered to be in a central position if there were individuals on all sides; at the border if there were other individuals on one side only; or at the periphery if there were no other group member in the circular area (Range et al., 2007). These positions were used as a proxy of the location of the monkeys within the group spread.

Unidirectional supplant interactions were used to establish the dominance rank or hierarchy between all individuals in the group. Dominance rank scores were calculated using a modification of the Elo rating method (Mielke et al., 2017), with individual dominance rank score values calculated daily, scaled between 0 (lowest-ranking individual) and 1 (highest-ranking individual) and then aggregated to estimate monthly average rank scores. Dominance ranks for males and females were combined to establish one common hierarchy for both sexes.

Since sooty mangabeys are mainly frugivorous (McGraw et al., 2007), fruit availability should determine food availability. The monthly productivity index of ripe fruit was used as an indicator of monthly food availability (Awa II and Talla, 2019). The fruit productivity index for each month is the sum of the fruit productivity indices of all fruit plant species included in the phenology. To obtain the ripe fruit productivity index for each species, the mean $\mathrm{DBH}$, the density and the percentage of fruiting plants of each species were multiplied (Anderson et al., 2005; Goné Bi, 2007).

\section{Models and statistics}

To analyze whether the likelihood of performing each activity was influenced by spatial positions of focal individuals within the group, their sex, their dominance rank and food availability, Generalized Linear Mixed Models (Baayen, 2008) were used with binomial error structure and log link function (McCullagh and Nelder, 1989). Models were conducted on the level of individual scans to test what determined the likelihood that a particular activity was shown at any given time. Three models were conducted, each testing two of the three activities against each other to determine the likelihood that one was chosen over the other.

Specifically, in model 1 (Table 1 for model parameters), the influence of within group spatial positions and sex of focal individuals and their interaction with dominance rank on the likelihood to feed, rest or travel has been tested. For this, as response, every combination of three dyadic comparisons of activities were analyzed: situations in which focal individuals travel with situations in which they rest (model 1.1, $\mathrm{n}=513$ ); situations in which focal individuals feed with situations in which they rest (model 1.2, $\mathrm{n}=1919)$; and situations in which focal individuals feed with situations in which they travel (model 1.3, $\mathrm{n}=1730$ ). The sex, dominance rank and within-group spatial positions of the focal were included as fixed effects in the models. Since a different effect of within group spatial position and dominance rank on the activity for each sex was expected, two two-way-interactions were included into the models, one interaction between the sex and within-group spatial positions of focal individuals, and one interaction between the sex and dominance rank of focal individuals. Monthly measures for food availability were included as control variable.

For model 2 (Table 1 for model parameters), how well dominance rank, sex, and their interaction with activity explained the likelihood of individuals to be central or not at any given time has been tested. As binomial response, all occurrences of focal 
individuals in the central position against all occurrences of them in the non-central positions (border and periphery) $(n=2081)$ were tested. Therefore, whether focal individuals were central or not central in each scan were compared based on dominance rank, sex, and activity. Here, the dominance rank, sex and activity of focal individuals were included as fixed effects. Since centrality was expected to be driven by the dominance rank but also by the sex of focal individuals, one two-way-interaction between the dominance rank and the sex of the focal was included in this model.

Prior to the analysis, all covariates have been z-transformed to a mean of zero and a standard deviation of one to get comparable estimates and facilitate the interpretation of the model results (Schielzeth, 2010). To avoid problems of interpretation and multi-collinearity of the dominance rank variable, since most males are usually higherranking than most females in sooty mangabeys, the dominance rank was standardized within sex testing whether highranking males and high-ranking females react differently to low-ranking individuals of each sex.

Furthermore, the focal subject identity $(\mathrm{N}=29$ individuals $)$, the month $(\mathrm{N}=14$ months) and date were included as random effects into the models. All possible random slopes were included within focal identity and within date and month, but not the correlation parameters between random intercepts and random slopes terms (Barr et al., 2013). The models were fitted in $\mathrm{R}$ version 3.4.1 ( $\mathrm{R}$ Development Core Team, 2015) using the function "glmer" of the R package "Ime4" (Bates et al., 2015). Variance inflation factors (Field, 2005) were calculated using the function VIF of the R-package car (Fox and Weisberg, 2011) applied to a standard linear model excluding the random effects, which showed that collinearity was not an issue (maximum VIF: 1.11). The statistical significance of full models was determined by comparing their fit with that of the null model (comprising the control variables and the random effects) (Forstmeier and Schielzeth, 2011), using a likelihood ratio test (Dobson and Barnett, 2008). P-values for the individual effects were based on likelihood ratio tests comparing the model including and excluding the effect (Barr et al., 2013). The nonsignificant interactions were removed from the model to reliably interpret the lower level terms included. Such removal was done only if the full-null model comparison revealed significance. $\mathrm{P}$-values $\leq 0.05$ were considered significant.

Table 1: Overview of model parameters present in the models fitted.

\begin{tabular}{|c|c|c|c|c|}
\hline Models & Responses & $\begin{array}{c}\text { Test } \\
\text { Parameters }\end{array}$ & $\begin{array}{c}\text { Control } \\
\text { Parameters }\end{array}$ & Random Effects \\
\hline 1.1 & $\operatorname{travel}(1) / \operatorname{rest}(0)$ & $\begin{array}{c}\text { SEX * } \\
\text { POSITION } \\
\text { SEX } * \text { Rank }\end{array}$ & Fruit. availabillity & $\begin{array}{c}\text { Focal ID } \\
\text { Day } \\
\text { Month }\end{array}$ \\
\hline 1.2 & feed(1)/rest $(0)$ & $\begin{array}{c}\text { SEX* } \\
\text { POSITION } \\
\text { SEX * Rank } \\
\end{array}$ & Fruit. availabillity & $\begin{array}{c}\text { Focal ID } \\
\text { Day } \\
\text { Month } \\
\end{array}$ \\
\hline 1.3 & feed(1)/travel $(0)$ & $\begin{array}{c}\text { SEX* } \\
\text { POSITION } \\
\text { SEX * Rank }\end{array}$ & Fruit. availabillity & $\begin{array}{c}\text { Focal ID } \\
\text { Day } \\
\text { Month }\end{array}$ \\
\hline 2 & central(1)/peripheral $(0)$ & $\begin{array}{l}\text { SEX * Rank } \\
\text { ACTIVITY }\end{array}$ & & $\begin{array}{c}\text { Focal ID } \\
\text { Day } \\
\text { Month }\end{array}$ \\
\hline
\end{tabular}




\section{RESULTS}

Impact of within group spatial positions, sex and dominance rank of focal individuals on the likelihood to feed, rest and travel

Model 1: The result was that individuals at the periphery were more likely to travel compared to individuals in the center, while individuals in the center were more likely to rest or feed.

The full null model comparison for model 1.1 , testing the likelihood to travel rather than rest, revealed a significant impact of position and sex on difference between traveling and resting (likelihood ratio test comparing full and null model: $\chi 2=28.29$, df $=7, \quad \mathrm{P}<0.001)$. None of the two-way interactions were significant. After removing the non-significant interaction terms, spatial position and sex effects were significant. While all individuals were more likely to be resting than traveling, individuals in the center had a much higher likelihood to be resting than those at the periphery (estimate $=1.02$, s.e. $=0.36, P=0.005 ;$ Table 2, Figure 1a). Moreover, males were more likely to be traveling than females (estimate $=0.48$, s.e. $=$ $0.22, \mathrm{P}=0.029$; Table 2, Figure 1b). There was no significant effect of dominance rank and food availability on the likelihood to travel rather than rest (Table 2).

The full null model comparison for model 1.2, investigating the likelihood to feed rather than to rest, showed a significant influence of position and sex on difference between feeding and resting (likelihood ratio test comparing full and null model: $\chi 2=21.22$, $\mathrm{df}=7, \mathrm{P}=0.003$ ). The interaction between spatial position and the sex of the focal individual revealed a trend $(\mathrm{P}=0.067$; Table 3 , Figure 2a) and the interaction between the dominance rank and the sex of the focal individual was significant $(\mathrm{P}=0.001$; Table 3 , Figure $2 \mathrm{~b}$ ). When at the periphery, females tended to spend more time feeding over resting than males (Figure 2a). Moreover, low-ranking males were more likely to be seen feeding rather than resting compared to high-ranking males (Figure 2b). There was no obvious dominance rank effect in females with regard to the frequency with which they feed or rest (Table 3).

The full null model comparison for model 1.3, targeting the likelihood to feed rather than to travel, indicated a significant effect of position and sex on difference between feeding and traveling (likelihood ratio test comparing full and null model: $\left.\chi^{2}=30.26, \mathrm{df}=7, \mathrm{P}<0.001\right)$. None of the twoway interactions was significant. After removing the non-significant interaction terms, spatial position and sex effects were significant. The results showed that individuals who were more peripheral were less likely to be seen feeding than traveling while individuals that were more central were more likely to be seen feeding than traveling (estimate $=-1.27$, s.e. $=0.29, \mathrm{P}<0.001$; Table 4 , Figure 3a). Both males and females had a higher likelihood to be feeding than to be traveling. However, females were more likely than males to be feeding rather than traveling (estimate $=-0.54$, s.e. $=0.22, \mathrm{P}=0.003$; Table 4, Figure 3b). Nevertheless, there was no obvious effect of dominance rank and food availability (Table 4).

To summarize, individuals at the periphery travelled more than individuals in the center do, independently of sex. Globally, male mangabeys travelled more than females while female individuals spent more time feeding and resting than males. However, there were no clear dominance rank differences among individuals that were seen feeding, resting or traveling.

Impact of rank, sex and activity on the likelihood of individuals to be central or not Model 2: The result reveals that high-ranking individuals and females were more likely to be in the center of the group. 
The full null model comparison for model 2, analyzing who is central or not central, revealed a significant difference between full and null model (likelihood ratio test comparing full and null model: $\chi 2=24.65$, $\mathrm{df}=5, \quad \mathrm{P}<0.001)$. The two-way interaction between sex and dominance rank was not significant. After removing the non-significant interaction term, sex and dominance rank effects were significant. More specifically, females were more likely to be central than males (estimate $=-0.60$, s.e. $=0.27, \mathrm{P}=0.026$; Table 5, Figure 4a). In addition, individuals that were feeding and resting are more likely to be central than individuals that were traveling (estimate $=0.77$, s.e. $=0.25$, $\mathrm{P}=0.002$; Table 5, Figure 4b). Higher-ranking individuals were more likely to be central than low-ranking individuals (estimate $=0.47$, s.e. $=0.11, \mathrm{P}<0.001$; Table 5, Figure 4c).
To summarize, high-ranking individuals and females were more likely to be central than low-ranking individuals and males. The impact of activity on centrality was confirmed with feeding and resting individuals more likely to be seen in the center of the group while traveling individuals were more likely to be observed at the periphery of the group.

To summarize, high-ranking individuals were more likely to be central than low-ranking individuals, independently of sex. Overall, females were more likely to be central than males. The impact of activity on centrality was confirmed with feeding and resting individuals more likely to be seen in the center of the group while traveling individuals were more likely to be observed at the periphery of the group.

Table 2: Result of final model 1.1: Influence of within group spatial positions and sex of focal individuals on the likelihood to travel or rest. Estimate and Standard Error from final model after removing all non-significant higher-order interactions, $\mathrm{z}$-values and p-values result of likelihood ratio test of the reduced model lacking this term with the final model. Full null model comparison: $\chi 2=28.28, \mathrm{df}=7, \mathrm{P}<0.001$.

\begin{tabular}{ccccc}
\hline Term & Estimate & SE & z-value & p \\
\hline Intercept & -1.33932 & 0.20435 & -6.554 & $(1)$ \\
Sex: Male $^{(3)}$ & 0.47888 & 0.22066 & 2.170 & 0.02999 \\
Position: Border $^{(4)}$ & 0.71193 & 0.21900 & 3.251 & 0.00115 \\
Position: Periphery $^{(4)}$ & 1.01933 & 0.36363 & 2.803 & 0.00506 \\
Rank $^{(5)}$ & -0.07518 & 0.13909 & -0.540 & 0.58887 \\
Fruit. Availability $^{(5)}$ & 0.13631 & 0.17747 & 0.768 & $(2)$ \\
\hline
\end{tabular}

\footnotetext{
Signif. codes: 0 ‘***’ 0.001 '**’ $0.01^{\text {‘*’ }} 0.05$ '.' 0.1 ' '1

(1) = not shown because of having a very limited interpretation

(2) $=$ control predictor

(3) $=$ reference level is Female

(4) $=$ reference level is Position: Central

(5) $=\mathrm{z}$-transformed, mean and standard deviation in Table 6
} 


\section{Impact of Position on likelihood to travel}

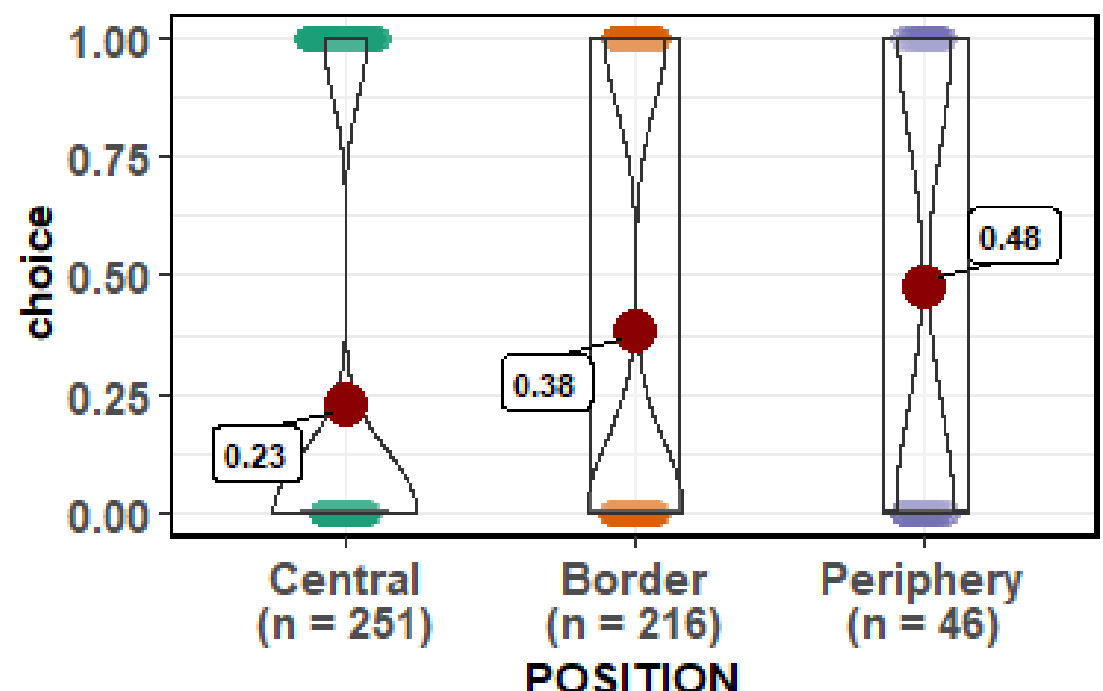

Travel or not $(0=$ Rest, $1=$ Travel $)$

(a)

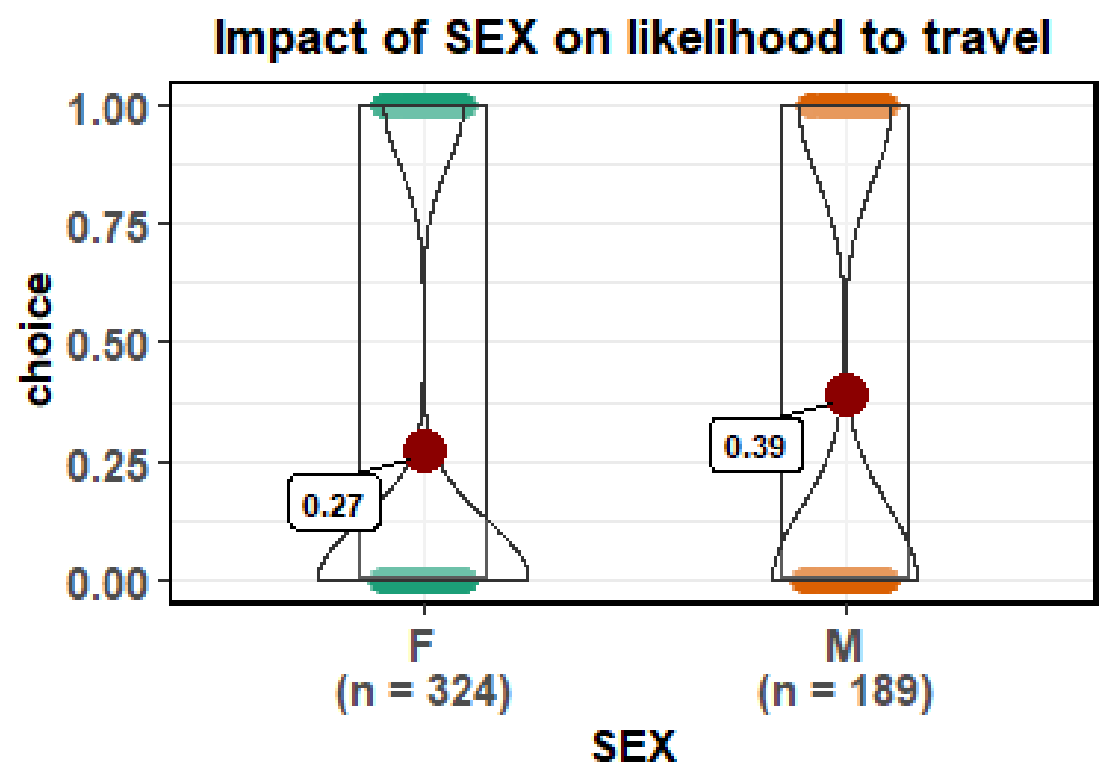

Travel or not $(0=$ Rest, $1=$ Travel $)$

(b)

Figure 1: The likelihood of individuals to be traveling or resting depending on the effect of within-group spatial position (a) and on the sex effect (b) (model 1.1). Shown are the probabilities to travel ( 1 denotes a higher number of traveling observations) or to rest ( 0 denotes a higher number of resting observations). 
Table 3: Result of full model 1.2: Influence of within group spatial positions and sex of focal individuals on the likelihood to feed or rest. Estimate and Standard Error from full model including all significant interactions, $\mathrm{z}$-values and $\mathrm{p}$-values result of likelihood ratio test of the reduced model lacking this term with the final model. Full null model comparison: $\chi 2=21.22, \mathrm{df}=7, \mathrm{P}=0.003$.

\begin{tabular}{ccccc}
\hline Term & Estimate & SE & z-value & p \\
\hline Intercept Sex: Male $^{(3)}$ & 1.506190 & 0.143709 & 10.481 & $(1)$ \\
Position: B order $^{(4)}$ & -0.004287 & 0.236742 & -0.018 & 0.98555 \\
Position: Periphery $^{(4)}$ & 0.108521 & 0.158334 & 0.685 & 0.49310 \\
Rank $^{(5)}$ & 0.745999 & 0.554416 & 1.346 & 0.17844 \\
Fruit. Availability $^{(5)}$ & 0.095967 & 0.102999 & 0.932 & 0.35148 \\
Sex: Male: Position: Border & 0.156150 & 0.108620 & 1.438 & $(2)$ \\
Sex: Male: Position: Periphery & -1.183444 & 0.647434 & -1.828 & 0.06756 \\
Sex: Male: Rank & -0.462952 & 0.149670 & -3.093 & 0.00198 \\
\hline
\end{tabular}

Signif. codes: 0 ‘***’ 0.001 '**’ 0.01 '*’ 0.05 '.’ $0.1^{\text {‘’ } 1}$

(1) = not shown because of having a very limited interpretation

(2) $=$ control predictor

(3) $=$ reference level is Female

(4) $=$ reference level is Position: Central

(5) $=$ z-transformed, mean and standard deviation in Table 6

Table 4: Result of final model 1.3: Influence of within group spatial positions and sex of focal individuals on the likelihood to feed or travel. Estimate and Standard Error from final model after removing all non-significant higher-order interactions, z-values and p-values result of likelihood ratio test of the reduced model lacking this term with the final model. Full null model comparison: $\chi 2=30.26, \mathrm{df}=7, \mathrm{P}<0.001$.

\begin{tabular}{ccccc}
\hline Term & Estimate & SE & z-value & $\mathbf{p}$ \\
\hline Intercept & 2.894344 & 0.213189 & 13.576 & $(1)$ \\
Sex: Male $^{(3)}$ & -0.543450 & 0.183546 & -2.961 & 0.00307 \\
Position: Border $^{(4)}$ & -0.532338 & 0.189982 & -2.802 & 0.00508 \\
Position: Periphery $^{(4)}$ & -1.270795 & 0.297245 & -4.275 & 0.0000191 \\
Rank $^{(5)}$ & -0.054627 & 0.089611 & -0.610 & 0.54212 \\
Fruit. Availability $^{(5)}$ & 0.000326 & 0.168869 & 0.002 & $(2)$ \\
\hline
\end{tabular}

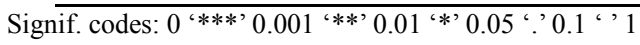

(1) = not shown because of having a very limited interpretation

(2) $=$ control predictor

(3) $=$ reference level is Female

(4) $=$ reference level is Position: Central

(5) $=\mathrm{z}$-transformed, mean and standard deviation in Table 6 


\section{Impact of Position and Sex on likelihood to feed}

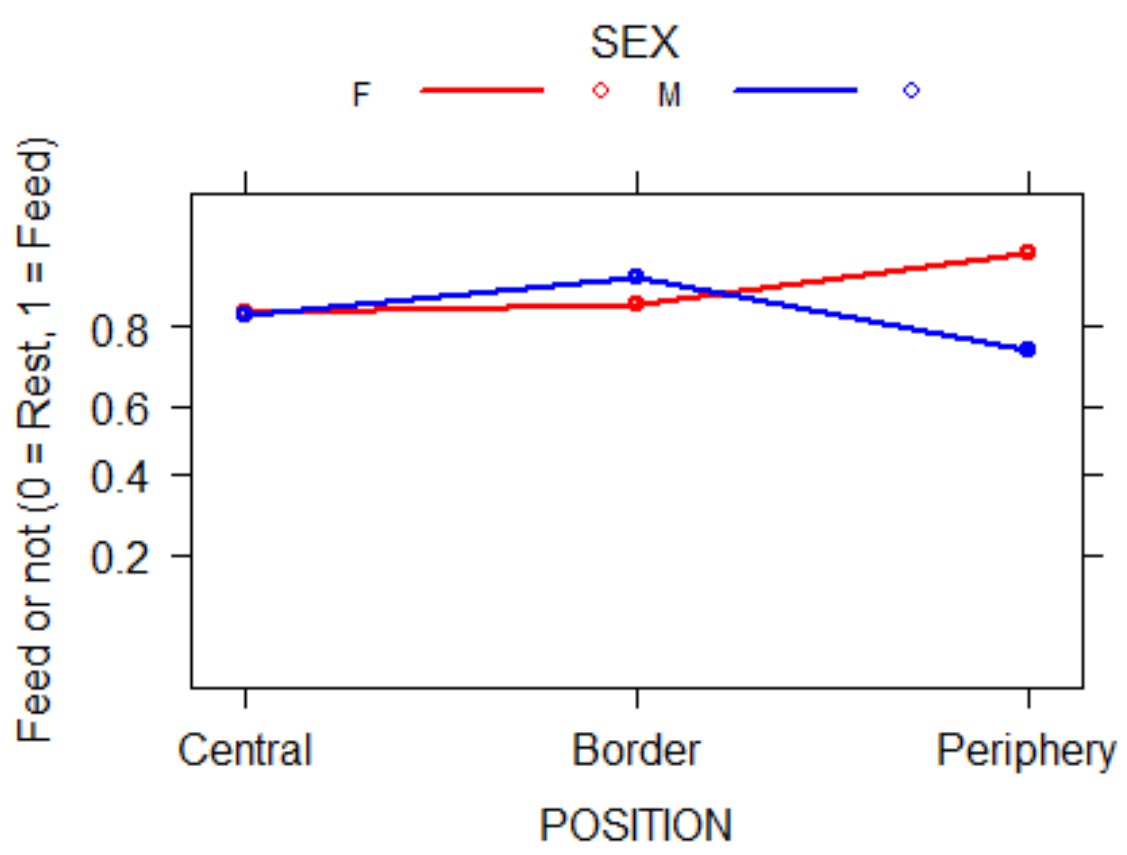

(a)

\section{Impact of Sex and Rank on likelihood to feed}

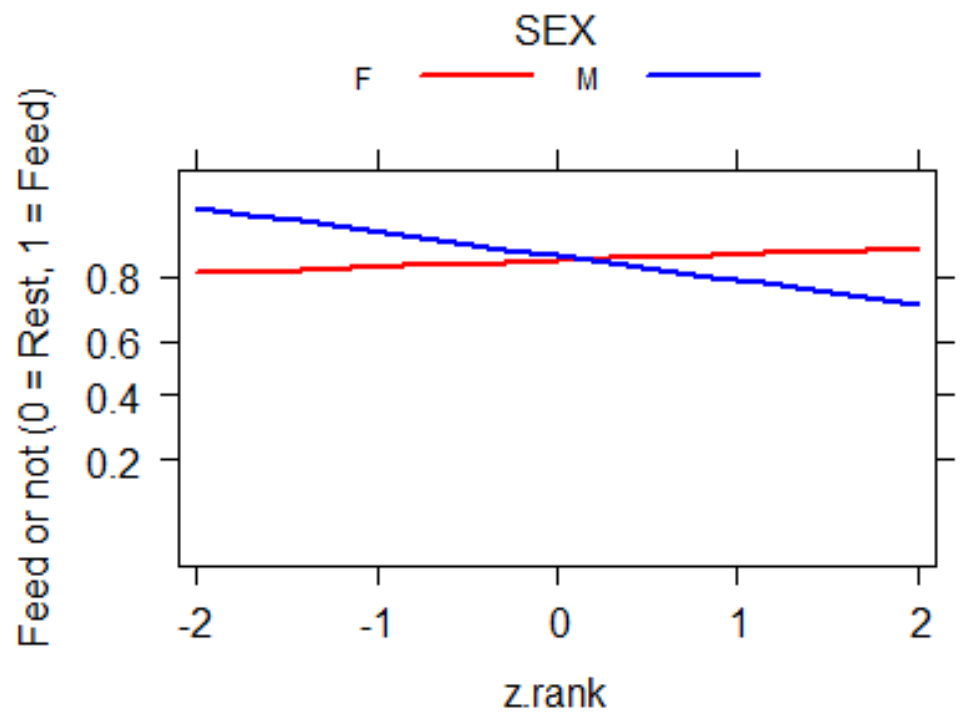

(b)

Figure 2: The likelihood of individuals to be feeding or resting depending on the effect of interaction of within-group spatial position with sex of individuals (a) and on the effect of interaction of dominance rank (z-standardized, original mean $=0.59$, s.d. $=0.29)$ with sex of individuals (b) (model 1.2). High values on the $\mathrm{x}$-axis of figure $2 \mathrm{~b}$ depict high individual rank. Shown are the probabilities to feed (1 denotes a higher number of feeding observations) or to rest ( 0 denotes a higher number of resting observations) as well as the model results (line red for females and line blue for males). 


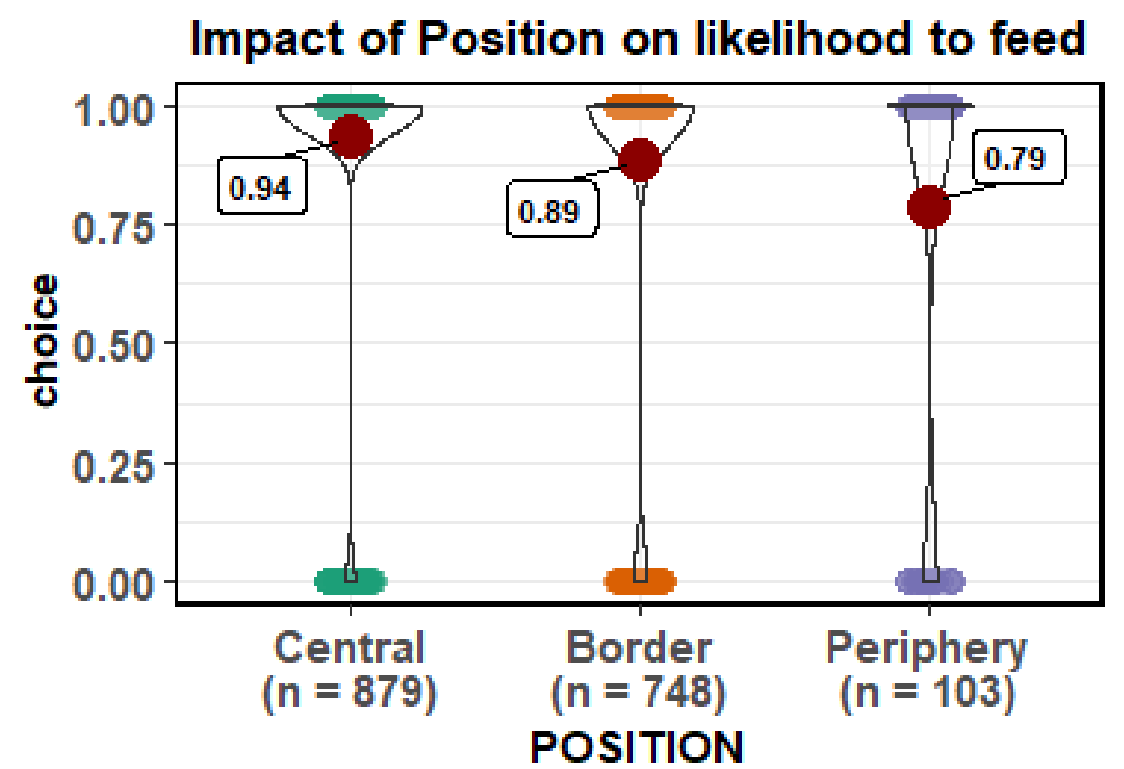

Feed or not $(0=$ Travel, $1=$ Feed $)$

(a)

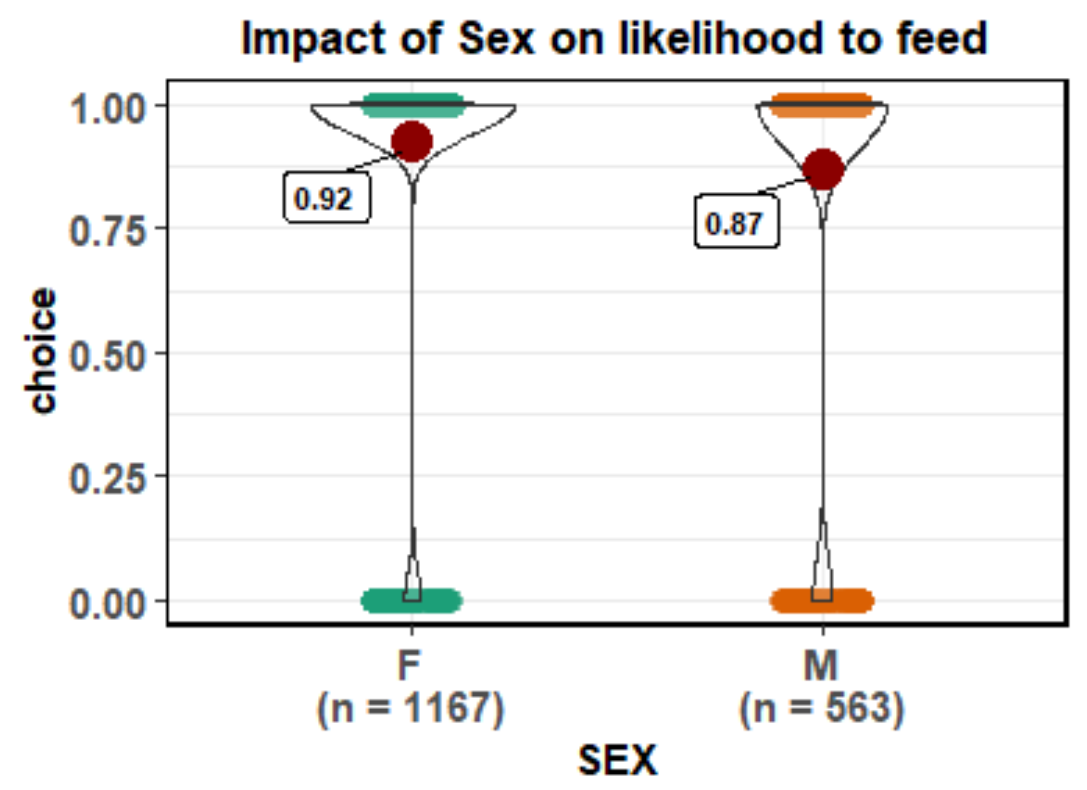

Feed or not $(0=$ Travel, $1=$ Feed $)$

(b)

Figure 3: The likelihood of individuals to be feeding or traveling depending on the effect of withingroup spatial position (a) and on the sex effect (b) (model 1.3). Shown are the probabilities to feed (1 denotes a higher number of feeding observations) or to travel (0 denotes a higher number of traveling observations). 
Table 5: Result of final model 2: Influence of activity, sex and rank of focal individuals on the likelihood to be central or not. Estimate and Standard Error from final model after removing all nonsignificant higher-order interactions, $z$-values and $p$-values result of likelihood ratio test of the reduced model lacking this term with the final model. Full null model comparison: $\chi 2=21.22, \mathrm{df}=7$, $\mathrm{P}=0.003$.

\begin{tabular}{ccccc}
\hline Term & Estimate & SE & z-value & p \\
\hline Intercept & -0.3134 & 0.2706 & -1.158 & $(1)$ \\
Rank $^{(4)}$ & 0.4709 & 0.1082 & 4.351 & 0.0000135 \\
Sex: Male $^{(2)}$ & -0.004287 & 0.236742 & -2.213 & 0.02688 \\
Activity: Feeding $^{(3)}$ & 0.6301 & 0.2191 & 2.876 & 0.00402 \\
Activity: Resting $^{(3)}$ & 0.7705 & 0.257 & 2.998 & 0.00272 \\
\hline
\end{tabular}

\begin{tabular}{|c|c|}
\hline \multicolumn{2}{|c|}{ Signif. codes: 0 ‘***’ 0.001 ‘**’ 0.01 ‘*’ 0.05 ‘’ 0.1 ‘’’1 } \\
\hline (1) & $=$ not shown because of having a very limited interpretation \\
\hline (2) & $=$ reference level is Female \\
\hline (3) & $=$ reference level is Activity: Traveling \\
\hline (4) & $=$ z-transformed, mean and standard deviation in Table 6 \\
\hline
\end{tabular}

Table 6: Original means and standard deviations of z-transformed variables for all models (Rank and Fruit. Availability).

\begin{tabular}{cccc}
\hline Model & Variable & Mean & SD \\
\hline 1.1 & Rank & 0.6099 & 0.2944 \\
& Fruit. Availability & 643.6941 & 306.9304 \\
1.2 & Rank & 0.5862 & 0.2893 \\
& Fruit. Availability & 676.9609 & 288.8448 \\
1.3 & Rank & 0.5836 & 0.2872 \\
& Fruit. Availability & 689.4214 & 290.01 \\
2 & Rank & 0.5884 & 0.2893 \\
\hline
\end{tabular}

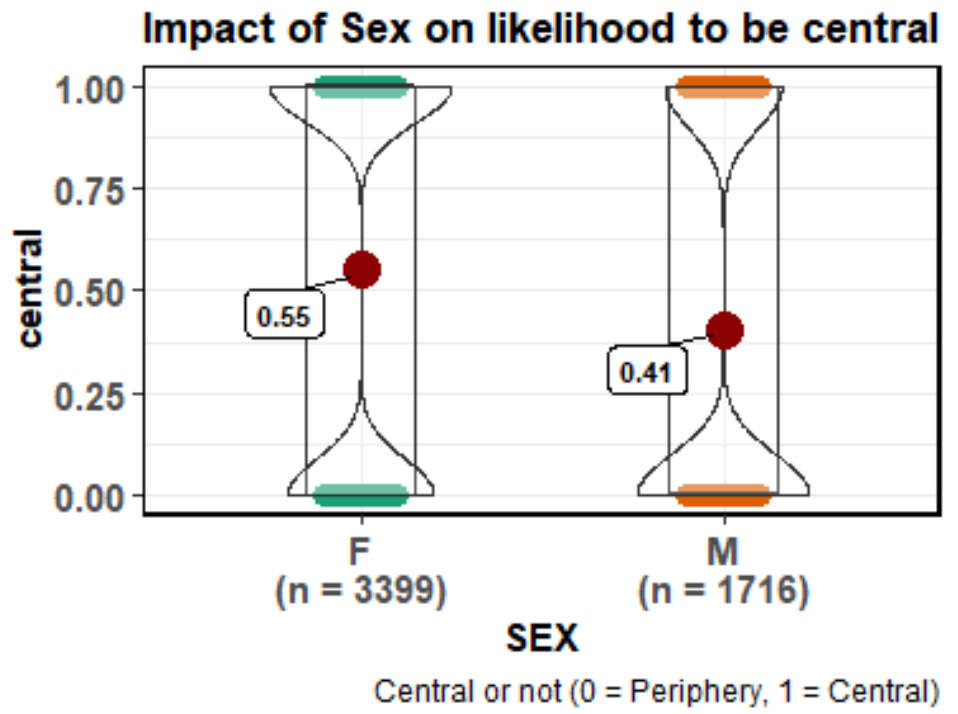

Figure 4a: The likelihood of individuals to be central or not depending on the sex effect (model 2). Shown are the probabilities to be central ( 1 denotes a higher number of observations of individuals in the center) or peripheral ( 0 denotes a higher number of observations of individuals both in the border and periphery positions). 


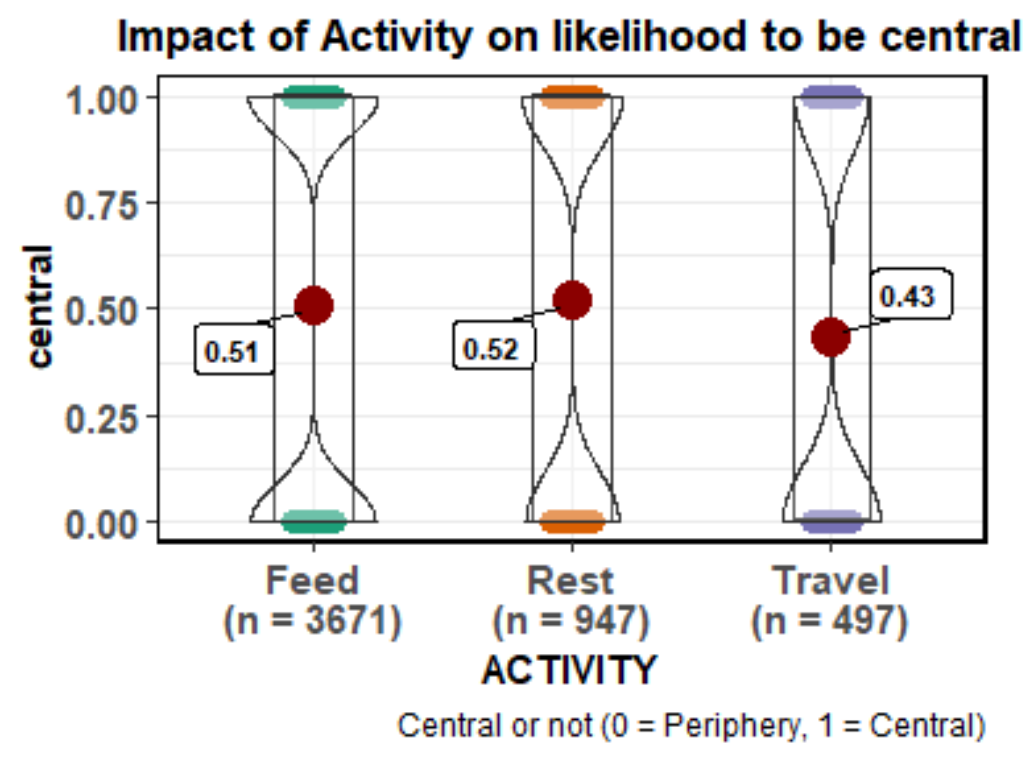

Figure 4b: The likelihood of individuals to be central or not depending on the activity effect (model 2 ). Shown are the probabilities to be central (1 denotes a higher number of observations of individuals in the center) or peripheral ( 0 denotes a higher number of observations of individuals both in the border and periphery positions).

\section{Impact of Rank on likelihood to be central}

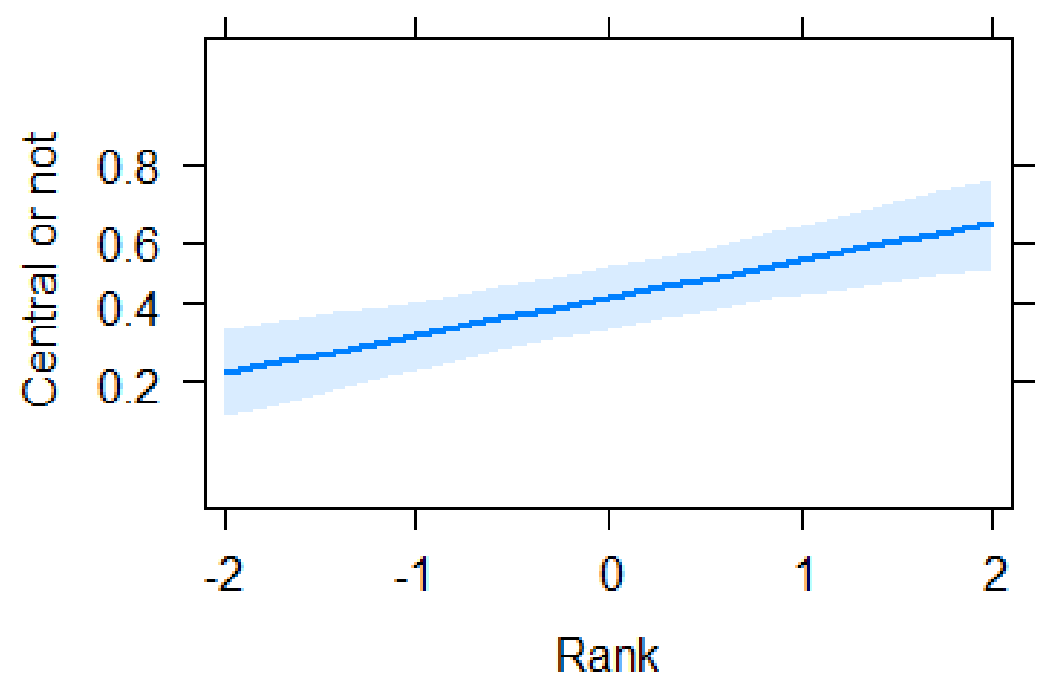

Figure 4c: The likelihood of individuals to be central or not depending on the rank effect (zstandardized, original mean $=0.59$, s.d. $=0.29$; model 2 ). High values on the $\mathrm{x}$-axis depict high individual rank. Individuals showed a significant positive effect with increasing rank. Shown are the probabilities to be central (1 denotes a higher number of observations of individuals in the center) or peripheral ( 0 denotes a higher number of observations of individuals both in the border and periphery positions) as well as the model results (line). 


\section{DISCUSSION}

This study aimed at investigating the impact of within group spatial positions on activity budgets in male and female sooty mangabeys, testing for dominance rank and controlling for food availability. The results showed that individuals travelled more when they were at the periphery, while they rested and fed more when they were central. This was independent of their dominance rank. Thus, there was a cost attached to being peripheral: individuals have to spend more time traveling and being vigilant, while in the center they can spend more time feeding or resting. At the same time, high-ranking individuals were more likely to be central. Thus, high dominance rank comes with clear benefits in sooty mangabeys: spending more time in a central position, individuals can focus on feeding and resting, while individuals that spend more time at the periphery have to spend more energy moving and looking out for predators. Females formed the core of the community, while males were more likely to be found at the periphery and traveling. These results indicate that females and high-ranking individuals benefit from their social status by adopting spatial positions in the community that impact their fitness positively.

Variation in individuals' fitness is associated to within-group spatial positions adopted by individuals in other primates (Di Bitetti and Janson, 2001; Hirsch, 2007; Morrell and Romey, 2008). Central individuals can dedicate more time to foraging than to vigilance, benefiting from conspecific vigilance and the dilution effects (Hirsch, 2007). This leads to increase the feeding rates of central individuals and likelihood to be observed feeding. Several studies have previously reported that central individuals have higher feeding rates in comparison with peripheral ones (Di Bitetti and Janson, 2001; Hirsch, 2007). Our results corroborated this assumption by showing that individuals spent more time feeding when they were more central. Nevertheless, intragroup feeding competition is high in the center of the group (Hirsch, 2007) and can influence individual foraging behaviors, with central individuals that may have lower feeding rates compared to peripheral individuals. We did not find evidence for this prediction, as central mangabeys fed more than peripheral ones. Our results reinforce the theory of foraging benefits for central individuals.

Decision making about the time spent in different activities (Korstjens et al., 2010) and the optimal spatial position to perform these activities are very important for the survival of diurnal primates. Female and male primates are expected to adjust their activitytime budgets according to their differing fitness priorities. Feeding is the most important activity for females on which they based their behavioral strategy. Females need to manage their energy efficiently, since their reproductive processes are energetically demanding. To face reproductive challenges, females must feed sufficiently (McCabe and Fedigan, 2007), but also get enough rest. We found that females, in comparison to males, spent more time at the center of the group, a safe spatial position (Range and Noë, 2002) where they can devote more time resting and particularly feeding, the most risky activity (Miller, 2002). By resting, individuals take time for recuperation, predator avoidance, digestion and thermoregulation. Resting time is an important component of animal behavior (Korstjens et al., 2010) that must attract more attention investigating in time-budgeting features. Our results showed that female mangabeys, compared to males, fed and rested more, but travelled less.

Feeding and resting are supposed to occur more at the center of the group, where, considering the high level of competition (Hirsch, 2007), sex and dominance rank effects are predictable. Even at the periphery, females, relative to males, are more likely to 
be seen feeding rather than resting. We did not find evidence of dominance rank effect in females with regard to the frequency with which females fed or rested, after the spatial position was accounted for. In males, in contrast, we found that low-ranking individuals fed more rather than rested compared to high-ranking individuals. Subordinates are able to increase substantially their food intake rates by concentrating on the less desirable food spots where little aggression occurred (Murray et al., 2006), otherwise they can be interrupted at any time when they are feeding, even in males, by aggression received or displacements from high-ranking individuals (Di Bitetti and Janson, 2001). They do not get access to highquality resources and thus they need to take advantage of any feeding opportunities. Therefore, they are more likely to be observed feeding. Dominant individuals have higher feeding success compared to subordinate individuals (Range and Noë, 2002). They feed efficiently at each feeding bouts and thus do not necessarily need to spend long time feeding. Moreover, high-ranking individuals benefit of grooming sessions from different group members (Mielke et al., 2018) during which they would be considered to resting. This explains why they spent more time resting compared to low-ranking individuals, and might also explain some of the differences we see between the sexes.

To explore additional explanation, it is important to distinguish between high-ranking and low ranking individuals who are more likely to be central. Our results showed that low-ranking individuals are more likely to be peripheral than high-ranking individuals who are more central, corroborating Heesen et al. (2015) results in macaques. Murray et al. (2006) suggested that individual spatial position preferences would change based on the lowest costs relative to benefits of spatial positions within the group. Using their dominance rank by defending aggressively the central positions, dominant individuals can exclude subordinates from these preferred positions and occupy them according to advantages of being at the center (Di Bitetti and Janson, 2001). There is a benefit to being high-ranking individuals. Subordinates, in contrast, were forced to spend more time at the periphery, with higher predation risks. Subordinates adapt their spatial positions according to the spatial distribution of dominants' aggressiveness (Murray et al., 2006).

\section{Conclusion}

Females and high-ranking mangabeys of both sexes spent more time at the safe spatial position in center of the group, and overall, spent more time feeding and resting. Males and low-ranking individuals of both sexes, in contrast, spent more time at the peripheral positions, where they also had to invest more in traveling. As we found differences between the times spent feeding, resting or traveling, females and higherranking individuals of both sexes benefit from their positions. High-ranking individuals of both sexes and females had a benefit over low-ranking individuals of both sexes and males, as they spent more time in central position, thus feed and rest safely. Possible reasons for the sex differences mirrored by the links between spatial positions, dominance rank and activity budgets are discussed to improve knowledge in social dynamics within wild primate groups.

\section{COMPETING INTERESTS}

The authors declare that they have no competing interests.

\section{AUTHORS' CONTRIBUTIONS}

BCG, JCKB, ZBGB and IK contributed to study conception and design. BCG contributed to acquisition of data. BCG, $\mathrm{AM}$ and $\mathrm{ZBGB}$ contributed to model development and analysis of data. All authors 
contributed to drafting of the manuscript and gave final approval for publication.

\section{ACKNOWLEDGEMENTS}

The authors wish to acknowledge the Ministry of Higher Education and Scientific Research, the Ministry of Environment and the Office Ivoirien des Parcs et Réserves (636/MINESUDD/OIPR/DG) for permissions to conduct the present study at the Tai National Park. We would particularly like to recognize the valuable help of all the team of Taï Chimpanzee Project, especially the field assistants, Simon Kannieu, Daniel Bouin, and the driver Sidiki Koné. We are extremely grateful to Dr. Roman M. Wittig, Director of Taï Chimpanzee Project, for his support and advice at every stage of the study.

\section{REFERENCES}

Altmann J. 1974. Observational study of behavior: sampling methods. Behaviour, 49(3-4): 227-266. DOI: https://doi.org/10.1163/156853974X005 34

Anderson DP, Nordheim EV, Moermond TC, Gone Bi ZB, Boesch C. 2005. Factors Influencing Tree Phenology in Taï National Park, Côte d'Ivoire 1. Biotropica: The Journal of Biology and Conservation, 37(4): 631-640. DOI: https://doi.org/10.1111/j.17447429.2005.00080.x

Awa II T, Talla NVK. 2019. Comparison of fruit tree richness and abundance as an indicator of food resource availability for the endangered Tauraco bannermani in Mount Oku and Mount Mbam, Western Highlands of Cameroon. International Journal of Biological and Chemical Sciences, 13(3): 1332-1342. DOI: 10.4314/ijbcs.v13i3.10

Baayen RH. 2008. Analyzing Linguistic Data: A Practical Introduction to Statistics using $R$. Cambridge University Press: Cambridge.
Barr DJ, Levy R, Scheepers C, Tily HJ. 2013. Random effects structure for confirmatory hypothesis testing: Keep it maximal. Journal of memory and language, $\quad \mathbf{6 8}(3)$ : 255-278. DOI: https://doi.org/10.1016/j.jml.2012.11.001

Bates D, Mächler M, Bolker B, Walker S. 2015. Fitting Linear Mixed-Effects Models using lme4. Journal of Statistical Software, $\quad$ 67(1): $\quad 1-48 . \quad$ DOI: 10.18637/jss.v067.i01

Di Bitetti MS, Janson CH. 2001. Social foraging and the finder's share in capuchin monkeys, Cebus apella. Animal Behaviour, 62(1): 47-56. DOI: https://doi.org/10.1006/anbe.2000.1730

Di Fiore A, Rodman PS. 2001. Time allocation patterns of lowland woolly monkeys (Lagothrix lagotricha poeppigii) in a neotropical terra firma forest. International Journal of Primatology, 22(3): 449-480. DOI: https://doi.org/10.1023/A:101075972956 7

Dobson AJ, Barnett A. 2008. An Introduction to Generalized Linear Models (3rd ed). Chapman and Hall/CRC: New York.

Field A. 2005. Discovering Statistics using SPSS. Sage: Thousand Oaks, CA, US.

Fonkwo SN, Mbida M, Angwafor TE, Ebua VB. 2015. Activity budget of Preuss's red colobus (Procolobus preussi) in Korup National Park, South-West region, Cameroon. International Journal of Biological and Chemical Sciences, 9(4): $\quad 1799-1808 . \quad$ DOI: http://dx.doi.org/10.4314/ijbcs.v9i4.6

Forstmeier W, Schielzeth H. 2011. Cryptic multiple hypotheses testing in linear models: overestimated effect sizes and the winner's curse. Behavioral Ecology and Sociobiology, 65(1): 47-55. DOI: https://doi.org/10.1007/s00265-0101038-5 
Fox J, Weisberg S. 2011. An R Companion to Applied Regression (2nd ed). Sage: Thousand Oaks, CA.

Goné Bi ZB. 2007. Régime alimentaires des chimpanzés, distribution spatiale et phénologie des plantes dont les fruits sont consommés par les chimpanzés du Parc national Taï. Thèse, Université de Cocody, Abidjan, Côte d'Ivoire, p. 6789.

Heesen M, Macdonald S, Ostner J, Schülke O. 2015. Ecological and social determinants of group cohesiveness and within-group spatial position in wild assamese macaques. Ethology, 121(3): 270-283. DOI: https://doi.org/10.1111/eth.12336

Hegab IM, Qian Z, Pu Q, Wang Z, Cai Z, Guo H, Wang H, Ji W, Hanafy AM, Su J. 2018. Gender difference in unconditioned and conditioned predator fear responses in Smith's zokors (Eospalax smithii). Global ecology and conservation, 16: e00503.

Hirsch BT. 2007. Costs and benefits of within-group spatial position: a feeding competition model. The Quarterly Review of Biology, 82(1): 9-27. DOI: https://doi.org/10.1086/511657

Koenig A, Scarry CJ, Wheeler BC, Borries C. 2013. Variation in grouping patterns, mating systems and social structure: what socio-ecological models attempt to explain. Philosophical Transactions of the Royal Society B: Biological Sciences, 368(1618): 20120348. DOI: https://doi.org/10.1098/rstb.2012.0348

Korstjens A H, Lehmann J, Dunbar R. 2010. Resting time as an ecological constraint on primate biogeography. Animal Behaviour, 79(2): 361-374. DOI: https://doi.org/10.1016/j.anbehav.2009.1 1.012

McCabe GM, Fedigan LM. 2007. Effects of reproductive status on energy intake, ingestion rates, and dietary composition of female Cebus capucinus at Santa
Rosa, Costa Rica. International Journal of Primatology, 28(4): 837-851. DOI: https://doi.org/10.1007/s10764-0079159-z

McCullagh P, Nelder J. 1989. Binary data. In Generalized Linear Models. Springer; 98-148.

McGraw WS, Zuberbühler K, Noë R. 2007. Monkeys Of The Taï Forest: An African Primate Community (Vol. 51). Cambridge University Press: Cambridge. Mielke A, Preis A, Samuni L, Gogarten JF, Wittig RM, Crockford C. 2018. Flexible decision-making in grooming partner choice in sooty mangabeys and chimpanzees. Royal Society open science, $\quad \mathbf{5}(7)$ : $172143 . \quad$ DOI: https://doi.org/10.1098/rsos.172143

Mielke A, Samuni L, Preis A, Gogarten JF, Crockford C, Wittig RM. 2017. Bystanders intervene to impede grooming in Western chimpanzees and sooty mangabeys. Royal Society open science, 4(11): 171296. DOI: https://doi.org/10.1098/rsos.171296

Miller LE. 2002. Eat Or be Eaten: Predator Sensitive Foraging Among Primates. Cambridge University Press: Cambridge.

Morrell LJ, Romey WL. 2008. Optimal individual positions within animal groups. Behavioral ecology, 19(4): 909919.

DOI:

https://doi.org/10.1093/beheco/arn050

Murray CM, Eberly LE, Pusey AE. 2006. Foraging strategies as a function of season and rank among wild female chimpanzees (Pan troglodytes). Behavioral ecology, 17(6): 1020-1028. DOI: https://doi.org/10.1093/beheco/arl042

Nascimento HE, Laurance WF. 2002. Total aboveground biomass in central Amazonian rainforests: a landscape-scale study. Forest ecology and management, 168(1-3): 311-321. DOI: 
https://doi.org/10.1016/S0378-

1127(01)00749-6

Ngueguim J, Dondjang J, Onana J, Ijang PT, Zapfack L, Noumi VN, Kengne O, Solefack CM. 2011. Moabi (Baillonella toxisperma Pierre): arbre à usage multiple de forêt dense humide du Cameroun. International Journal of Biological and Chemical Sciences, 5(6): 2395-2406.

DOI:

http://dx.doi.org/10.4314/ijbcs.v5i6.19

R Development Core Team. 2015. R: A Language and Environment for Statistical Computing. In $R$ Foundation for Statistical Computing. Vienna: Austria.

Range F, Förderer T, Storrer-Meystre Y, Benetton C, Fruteau C. 2007. The Structure of Social Relationships among Sooty Mangabeys in Taii. In Monkeys of the Taï Forest: An African Primate Community, McGraw W, Zuberbühler K, Noë R (Ed). Cambridge University Press: Cambridge.

Range F, Noë R. 2002. Familiarity and dominance relations among female sooty mangabeys in the Taï National Park.
American Journal of Primatology: Official Journal of the American Society of Primatologists, 56(3): 137-153. DOI: https://doi.org/10.1002/ajp.1070

Range F, Noë R. 2005. Can simple rules account for the pattern of triadic interactions in juvenile and adult female sooty mangabeys? Animal Behaviour, 69(2): $\quad 445-452 . \quad$ DOI: https://doi.org/10.1016/j.anbehav.2004.0 2.025 .

Schielzeth H. 2010. Simple means to improve the interpretability of regression coefficients. Methods in Ecology and Evolution, 1(2): 103-113. DOI: https://doi.org/10.1111/j.2041210X.2010.00012.x

Tiebre M, Kouame D, Vroh ATB, N'da K, Adou Y. 2014. Stratégies et potentiel d'invasion des massifs forestiers par Hopea odorata Roxb.(Dipterocarpaceae): cas du Parc National du Banco en Côte d'Ivoire. International Journal of Biological and Chemical Sciences, 8(2): 666-679.

DOI: http://dx.doi.org/10.4314/ijbcs.v8i2.23. 